\title{
Linguagem e verdade: A relação entre Schopenhauer e Nietzsche em Sobre verdade e mentira no sentido extramoral
}

\author{
Fernando de Sá Moreira*
}

\begin{abstract}
Resumo: Pretendemos investigar a compreensão dos conceitos de verdade e linguagem no primeiro período de Nietzsche e demonstrar como a crítica à linguagem se relaciona com os conceitos de vontade, intelecto, intuição e razão de Schopenhauer. Segundo nossa interpretação, em oposição a Schopenhauer, o jovem Nietzsche identifica os conceitos de razão e linguagem e interpreta o intelecto como um processo pulsional. Tal alteração resultou na rejeição da proposta de uma metafísica da vontade e provocou mudanças significativas na interpretação dos papéis da arte, da ciência e da filosofia em relação aos propostos por Schopenhauer.

Palavras-chave: Schopenhauer - Nietzsche - verdade - linguagem intuição - intelecto
\end{abstract}

No início do texto de Sobre verdade e mentira no sentido extramoral, Nietzsche apresenta uma curiosa fábula para ilustrar o caráter efêmero do conhecimento humano:

Em algum remoto recanto do universo, que se deságua fulgurantemente em inumeráveis sistemas solares, havia uma vez um astro, no qual animais astuciosos inventaram o conhecimento. Foi o minuto mais audacioso e hipócrita [verlogenste] da "história universal" [Weltgeschichte]: mas, no fim das contas, foi apenas um minuto. Após alguns respiros da natureza, o astro congelou-se, e os astuciosos animais tiveram de morrer. Alguém poderia, desse modo, inventar

\footnotetext{
* Doutorando da Pontifícia Universidade Católica do Paraná (PUCPR), Curitiba, PR, Brasil. E-mail: fsmoreira@ymail.com.
} 
Moreira, F. S.

uma fábula e ainda assim não teria ilustrado suficientemente bem quão lastimável, quão sombrio e efêmero, quão sem rumo e sem motivo se destaca o intelecto humano no interior da natureza; houve eternidades em que ele não estava presente; quando ele tiver passado mais uma vez, nada terá ocorrido. Pois, para aquele intelecto, não há nenhuma missão ulterior que conduzisse para além da vida humana. Ele é, ao contrário, humano, sendo que apenas seu possuidor e gerador o toma de maneira tão patética, como se os eixos do mundo girassem nele. Mas se pudéssemos pôr-nos de acordo com o mosquito, aprenderíamos então que ele também flutua pelo ar com esse pathos e sente em si o centro esvoaçante deste mundo. Na natureza, não há nada tão ignóbil e insignificante que, com um pequeno sopro daquela força do conhecimento, não inflasse, de súbito, como um saco e assim como todo carregador de peso quer ter seu admirador, o mais orgulhoso dos homens, o filósofo, acredita ver por todos os lados os olhos do universo voltados telescopicamente na direção de seu agir e pensar (WL/VM 1, KSA 1.875).

Na passagem apresentada, Nietzsche expõe a fragilidade do intelecto humano, assim como a sua leviandade, caso tomemos como medida a "história universal". O surgimento e o desaparecimento do conhecimento marcam apenas um "minuto" dessa história, um minuto que, quando tiver passado, "nada terá ocorrido". No entanto, para o homem, o conhecimento o coloca ilusoriamente como o próprio eixo do mundo, gerando uma comum supervalorização do conhecimento, muitas vezes taxado como "divino" e de natureza e objetivos superiores, para além da vida humana. No entanto, Nietzsche cedo adverte sobre a subordinação do intelecto aos limites da vida humana. $\mathrm{O}$ intelecto não conduz a nenhuma verdade além da vida. Em última instância, o intelecto é "naturalizado" por Nietzsche. Sua função é semelhante à das demais partes do corpo. Sua missão só existe no interior dos limites da vida ${ }^{1}$.

1 Deve-se entender aqui a noção de "naturalização" do intelecto em contraposição com a 
Na sequência do texto, Nietzsche deixa mais claro qual seria a verdadeira função do intelecto: "Como um meio para a conservação do indivíduo, o intelecto desenrola suas principais forças na dissimulação [Verstellung], pois esta constitui o meio pelo qual os indivíduos mais fracos, menos vigorosos, conservam-se, como aqueles aos quais é denegado empreender uma luta pela existência [Kampf um die Existenz] com chifres e presas afiadas" (WL/VM 1, KSA 1.876).

A natureza do intelecto é definida, portanto, como dissimulação e sua função é a de arma na luta pela existência. Em outras palavras, para Nietzsche, o papel do intelecto não consistiria em um instrumento de acesso à verdade, como suporia a compreensão divinizante do intelecto. Afinal, se a própria natureza do intelecto é definida como dissimulação e a busca da verdade não é sua meta, torna-se problemático pensar a possibilidade de um puro impulso à verdade. Nas palavras de Nietzsche: "[...] quase nada é mais incompreensível do que como pôde vir à luz entre os homens um honesto e puro impulso à verdade [ehrlicher und reiner Trieb zur Wahrheit]" (WL/VM 1, KSA 1.876, tradução modificada). Em última instância, esse impulso à verdade pode ser entendido como a busca da filosofia pela coisa em si, que é definida por Nietzsche como "a pura verdade sem quaisquer consequências [reine folgenlose Wahrheit]" (WL/VM 1, KSA 1.879).

O filósofo aponta também o caráter antropomórfico do conhecimento humano, pois, ainda que frequentemente o homem encare o conhecimento e a verdade como o conhecimento absoluto da realidade, esse pathos da verdade se dá apenas em função da própria limitação perspectiva do intelecto humano. Como Nietzsche afigura na fábula que abre o texto: se pudéssemos nos entender com um mosquito perceberíamos que ele também se encontra sob o mesmo pathos. Mesmo que exposto apenas de forma hipotética,

noção de uma "divinização" do intelecto. Não se trata de entendê-lo em termos estritamente biológicos ou de acordo com hipóteses materialistas, mas de interpretá-lo como um instrumento da vida, compreendê-lo no e para o processo da efetividade. 
o argumento visa a denunciar a fragilidade e efemeridade do conhecimento humano. Ele é, para Nietzsche, uma construção humana, portanto, completa e necessariamente antropomórfico.

Podemos dividir o texto Sobre verdade e mentira no sentido extramoral em três momentos teóricos centrais: 1) análise do conceito e da possibilidade do conhecimento da verdade; 2) análise do sentido de um puro impulso à verdade; 3) Desenvolvimento das consequências práticas da teoria exposta a partir de dois tipos fundamentais de homem - o homem intuitivo e o homem racional.

No que concerne ao conceito de verdade, Nietzsche o define do seguinte modo:

O que é, pois, a verdade? Um exército móvel de metáforas ${ }^{2}$, metonímias $^{3}$, antropomorfismos, numa palavra, uma soma de relações humanas que foram realçadas poética e retoricamente, transpostas e adornadas, e que, após uma longa utilização, parecem a um povo consolidadas, canônicas e obrigatórias: as verdades são ilusões das quais se esqueceu que elas assim o são, metáforas que se tornaram desgastadas e sem força sensível, moedas que perderam seu cunho [Bild] e agora são levadas em conta apenas como metal, e não mais como moedas (WL/VM 1, KSA 1.880, tradução modificada).

Como o trecho acima pretende deixar claro, o movimento de análise do conceito de verdade em Nietzsche passa necessariamente por uma análise da linguagem e, consequentemente, também dos povos e da cultura. Com o enquadramento da verdade no âmbito da linguagem, o filósofo compreende que a possibilidade do conhecimento verdadeiro depende da possibilidade da língua dizer

2 O Nachlass/FP 1872-1873, 19[249], KSA 7.498, indica o que Nietzsche compreende como metáfora: "Metáfora significa tratar como igual algo que, num dado ponto, foi reconhecido como semelhante".

3 O Nachlass/FP 1872-1873, 19[242], KSA 7.495, esclarece o sentido de metonímia: “O juízo sintético descreve uma coisa de acordo com suas consequências, isto é, essência e consequências são identificadas, quer dizer, uma metonímia”. 
a verdade; e, com o enquadramento da verdade no âmbito das relações humanas, o filósofo deixa entrever que a verdade é, no limite, uma convenção social, portanto, moral.

O movimento de inserção da verdade no âmbito da linguagem parece ter suas origens nos estudos de filologia conduzidos pelo jovem Nietzsche. Mas, acreditamos que também podemos encontrá-las no debate com a filosofia schopenhaueriana. Embora Nietzsche não siga exatamente os mesmos passos de Schopenhauer, não podemos ignorar que também em Schopenhauer o a verdade está em relação com a linguagem. Segundo nossa hipótese, o jovem Nietzsche se distancia da metafísica da vontade ao interpretar a relação entre razão e linguagem de modo distinto ao de Schopenhauer e compreender a atividade do intelecto como um processo pulsional. Em última instância, tais considerações resultam na rejeição da oposição vontade-intelecto de Schopenhauer, mas na preservação da relação intuição-razão ${ }^{4}$.

A teoria schopenhaueriana parte da afirmação da idealidade de nossa percepção do mundo: o mundo é representação. Isso significa que nosso contato ordinário com o mundo se dá a partir da relação entre o sujeito e os objetos que a ele se apresentam. Complementarmente, Schopenhauer afirma que além da representação existe uma outra realidade, a coisa em si. Segundo este ponto de vista, o mundo possui "dois lados": o fenômeno (chamado de "representação") e a coisa em si (chamada de "vontade"). Este aparato conceitual preten-de, entre outras coisas, bem determinar o lugar próprio da filosofia. Para Schopenhauer, a atividade filosófica possui basicamente dois grandes campos de atuação: a teoria do conhecimento e a metafísica. $\mathrm{O}$ pensador alemão chega a considerar que todo

4 Escolhemos desenvolver nossa hipótese a partir do texto de Sobre verdade e mentira no sentido extramoral, um opúsculo redigido em 1873 por Nietzsche. A obra não apresenta nenhuma crítica explícita ao sistema schopenhaueriano, mas acreditamos poder encontrar diversas contraposições veladas. Essas contraposições podem fornecer as raízes de algumas críticas mais contundentes de Nietzsche a Schopenhauer que começam a surgir depois de Humano, demasiado humano. 
Moreira, F. S.

sistema filosófico sério deveria iniciar com uma bem fundamentada teoria do conhecimento. Quanto à metafísica, seria dividida em três campos inter-relacionados: metafísica da natureza, metafísica do belo e metafísica dos costumes ${ }^{5}$.

Como afirmamos, toda representação é uma relação entre sujeito e objeto. Segundo Schopenhauer, existem quatro classes distintas de objetos para o sujeito. Por estarem em âmbitos distintos, cada classe de objetos é regida por leis próprias que devem ser observadas particularmente e não podem ser confundidas entre si. Identificar corretamente cada uma das leis que regem cada uma das classes de objetos permitiria a correta aplicação do princípio de razão e a correta delimitação dos limites do conhecimento humano ${ }^{6}$.

As quatro classes de objetos seriam: (1) as representações intuitivas empíricas; (2) as representações abstratas; (3) as formas puras da intuição (tempo e espaço); e (4) a vontade empírica. A primeira classe de objetos corresponde aos objetos materiais, presentes no tempo e situados no espaço, obtidos por meio da sensibilidade e do entendimento, regidos pelo princípio de razão do vir-a-ser (a lei de causalidade). A segunda classe de objetos corresponde às representações abstratas, os conceitos, acessíveis pela razão e regidos pelo princípio de razão do conhecer (a lei de justificação dos juízos). A terceira classe de objetos corresponde ao tempo e ao espaço, enquanto formas puras da intuição sensível, acessíveis pela sensibilidade pura, regidos pelo princípio de razão do ser (lei de sucessão no tempo e de situação no espaço). A quarta classe de objetos corresponde à vontade empírica, tal como é apresentada no sentido interno para cada sujeito percipiente. Os objetos das primeira, terceira e quarta classes são obtidos por meio da intuição,

5 Cf. SCHOPENHAUER, A. Respuestas Filosóficas a la ética, a la ciencia y a la religión. Trad. Miguel Urquiola. Madrid: EDAF, 1996, p. 205-207.

6 Cf. SCHOPENHAUER, A. De la cuádruple raíz del principio de razón. Trad. L-E. Palacios. Madrid: Gredos, 1998, p. 31-32. 
seja ela pura ou empírica, obtidas pelo sentido interno ou externo. A segunda classe de objetos, por sua vez, tem seu lugar na razão.

A segunda classe de objetos possui uma característica própria frente às demais: enquanto na intuição o material dos objetos é fornecido na própria intuição, nas representações abstratas o material com o qual a razão trabalha deve ser colhido em um lugar diferente da própria razão: o material da razão é obtido nos objetos da intuição. Segundo o pensamento schopenhaueriano, os conceitos são abstrações realizadas a partir de intuições, pois a razão não pode criar conceitos sozinha, tampouco existiriam conceitos inatos. Por essa razão, Schopenhauer chama os conceitos de "representações de representações", uma vez que, mesmo os conceitos mais abstratos, sempre são, direta ou indiretamente, abstrações dos objetos da intuição. Os primeiros conceitos são abstraídos diretamente das intuições, só posteriormente os conceitos podem ser formados a partir de abstrações de outros conceitos. Quanto mais abstrato é um conceito, mas distante ele está de sua origem, a intuição ${ }^{7}$. Conforme vimos, a oposição entre razão e intuição está fundamentada na primazia da última sobre a primeira.

Com relação à verdade, Schopenhauer afirma que ela refere-se exclusivamente ao reino das representações abstratas. Como afirma o filósofo: "A verdade é, portanto, a relação de um juízo com algo diferente dele, que se chama sua razão [Grund]"s; o juízo, por sua vez, é uma relação entre esferas conceituais. Como existem diferentes tipos de objetos para o sujeito, existem também diferentes classes de verdade: (1) verdade empírica, quando a razão do juízo consiste em sua relação com as representações intuitivas; (2) verdade lógica, quando a veracidade do juízo se funda na relação estritamente lógica entre juízos (a validade de um silogismo);

7 Cf. SCHOPENHAUER, A. O mundo como vontade e representação. Trad. J. Barboza. São Paulo: Unesp, 2005, p. 87.

8 Idem, 1998, p. 158-159. 
Moreira, F. S.

(3) verdade transcendental, quando o juízo se refere às formas puras da intuição; (4) verdade metalógica, quando o juízo se refere às quatro leis do pensamento 9 .

No caso de um juízo expressar corretamente o modo de existência de um objeto, tem-se uma verdade, caso contrário, tem-se um erro. No entanto, no âmbito da intuição, fora do domínio dos conceitos e da razão, não há verdade ou erro. Ainda que o pensador admita a existência de ilusões, uma ilusão não é uma "intuição falsa", assim como uma realidade não é uma "intuição verdadeira". Nas palavras de Schopenhauer: "À verdade se opõe o erro como engano da razão, à realidade se opõe a ilusão como engano do entendimento ${ }^{10}$." A verdade fica delimitada, então, a uma relação entre conceitos.

A partir das considerações anteriores, o filósofo alemão pretende demonstrar o descompasso existente na relação entre razão e intuição. Enquanto os diversos objetos da intuição parecem consonantes entre si, ainda que determinados em reinos diferentes, os objetos da razão podem se apresentar com dissonâncias. Um objeto da intuição empírica, por exemplo, apresenta-se no tempo e no espaço, de modo que as leis que regem as intuições puras do tempo e do espaço também valem, dentro de seus âmbitos limitados de atuação, para as intuições empíricas. Essa relação entre as duas classes de objetos garante, por exemplo, a objetividade da aritmética e da geometria: uma vez que os objetos empíricos permeiem o espaço, as leis da geometria valem para tais objetos. Em última

9 No $\$ 18$ de $O$ mundo como vontade e representação, Schopenhauer cita uma quinta forma de verdade, a qual chamou de "verdade filosófica". Trata-se da expressão da identidade entre corpo e sujeito do querer, cuja relevância no sistema schopenhaueriano é constituir o caminho pelo qual podemos obter conhecimento mais adequado possível da coisa em si. Não nos deteremos na análise desse tipo de verdade, pois, como o próprio filósofo afirma, é "toto coelo" diferente das verdades citadas anteriormente e não pode ser afirmada pelo princípio de razão. Entendemos que a abordagem nietzschiana do conceito de verdade inviabiliza, desde a concepção geral, aquela que foi chamada por Schopenhauer de "verdade filosófica", uma vez que rejeita a oposição entre coisa em si e fenômeno.

10 Idem, 2005, p. 68.

280 I Cad. Nietzsche, São Paulo, n. 33, p. 273-300, 2013. 
análise, as verdades empírica e transcendental não entram em contradição entre si, pois as próprias intuições das formas puras do tempo e do espaço compõem e possibilitam as intuições empíricas. Uma verdade lógica, no entanto, pode estar em contradição com as demais formas de verdade, conquanto que o fundamento de cada um dos juízos que formam o silogismo não seja averiguado. Tudo se passa de acordo com a distinção tradicional entre verdade e validade na lógica. A razão é capaz de montar um sistema de juízos inverídicos, mas em que a forma lógica permita extrair conclusões válidas. Neste caso, a verdade lógica se baseia justamente na forma do silogismo e não se preocupa com a veracidade de cada um dos juízos. Em todo caso, a identificação da possibilidade de contradição entre uma verdade lógica e as demais formas de verdade não direciona Schopenhauer a uma teoria de antilogias aos moldes sofísticos. Trata-se neste caso de estabelecer o âmbito próprio de julgamento de cada forma de verdade, de modo que, para além da verdade lógica, deve-se buscar a veracidade de cada um dos juízos que constituem o silogismo. Uma verdade lógica baseada em juízos em desacordo com as demais formas de verdade não tem, por exemplo, o mesmo valor de uma verdade transcendental.

Como consequência da delimitação da verdade ao domínio das representações abstratas, a verdade está também extremamente aproximada da linguagem. Afinal, como Schopenhauer define, a linguagem também é um fruto da relação racional entre conceitos ${ }^{11}$. A linguagem torna-se, portanto, o campo de aplicação da verdade. Todavia, para Schopenhauer, a linguagem não coincide completamente com a totalidade das relações abstratas entre conceitos. Um conceito nem sempre é bem representado por uma palavra; fato esse observável na relação entre as diversas línguas. Do mesmo modo, uma língua pode ser gramaticalmente incapaz de expressar alguma

11 Cf. Idem, 2005, p. 87. 
Moreira, F. S.

relação determinada entre conceitos ${ }^{12}$. A esfera da linguagem e das representações abstratas se adequam apenas aproximadamente. Ocorre, por exemplo, de uma mesma palavra ser empregada para a representação de mais de um conceito, abrindo-se espaço para um equívoco na linguagem que não existe na razão. Em razão da mesma inadequação, existem diferenças consideráveis entre diversas línguas, quando o modo de operação da razão é o mesmo em todos os homens. Tal inadequação abre caminho para existência de uma dialética erística (retórica sofística) e fundamenta o elogio que Schopenhauer promove ao sânscrito, ao latim, ao grego e ao alemão como modelos de línguas mais adequadas para a correta expressão de relações entre conceitos ${ }^{13}$.

$\mathrm{O}$ conceito de linguagem em Nietzsche, no entanto, é mais amplo do que o de Schopenhauer, compreendendo mesmo a atividade racional como uma atividade propriamente linguística. Portanto, nesse primeiro momento de produção intelectual, Nietzsche opera com bases teóricas semelhantes - a diferença entre intuição e razão -, mas é mais radical que Schopenhauer quando posiciona completamente a verdade no âmbito da linguagem. Para Schopenhauer a ideia de verdade está ligada às relações entre conceitos, que para ele constitui um âmbito pré-linguístico. Entretanto, para Nietzsche também as operações racionais contam entre as atividades linguísticas. Em função desta ampliação, Nietzsche analisa a possibilidade de conhecimento da verdade enfocando a problematização da linguagem. "[...] como ficam as convenções da linguagem? São talvez produtos do conhecimento, do sentido da verdade [Wahrheitssinnes]: as designações e as coisas [Dinge] se recobrem? Então a linguagem é a expressão adequada de todas as realidades [Realitäten]?" (WL/VM 1, KSA 1.878). Em outros termos: uma vez que a verdade está colocada no âmbito da linguagem, existiria a

12 Cf. SCHOPENHAUER, A. A arte de escrever. Trad. Pedro Süssekind. Porto Alegre: L\&PM, 2009, p. 149.

13 Cf. Ibid., p. 145-147.

282 I Cad. Nietzsche, São Paulo, n. 33, p. 273-300, 2013. 
possibilidade do conhecimento da verdade, enquanto adequação entre uma coisa e uma designação? Qual a possibilidade da linguagem abarcar a "coisa em si"?

Schopenhauer responderia à primeira questão afirmativamente, desde que entendamos "coisas" como elementos pertencentes à esfera da representação e que existem línguas mais adequadas que outras para expressão da realidade. Entrementes, responderia negativamente à segunda questão. Isso acontece devido à separação entre intuição e razão e à compreensão de que os conceitos recebem toda a sua matéria direta ou indiretamente da intuição, ou seja, a compreensão de que os conceitos são mais vazios do que os objetos da intuição e só podem referir-se a tais objetos. Para Schopenhauer, um juízo jamais pode se referir adequadamente à coisa em si. Por sua vez, a resposta de Nietzsche para ambas as questões parecem ser negativas, como demonstra a seguinte afirmação:

Apenas por esquecimento pode o homem alguma vez chegar a imaginar que detém uma verdade no grau ora mencionado [como adequação da linguagem com a realidade]. Se ele não espera contentar-se com a verdade sob a forma da tautologia, isto é, com invólucros vazios [leeren Hülsen], então irá permutar eternamente ilusões por verdades. O que é uma palavra? A figuração [Abbildung] sonora de um estímulo nervoso. Mas deduzir do estímulo nervoso uma causa fora de nós já é o resultado de uma aplicação falsa e injustificada do princípio de razão [Satzes vom Grunde] (WL/VM 1, KSA 1.878, tradução modificada).

Ao se questionar pelo estatuto de uma palavra, Nietzsche pretende mostrar os antropomorfismos e arbitrariedades ligadas ao surgimento das línguas. Para tanto, faz a análise de três exemplos principais: Em primeiro lugar, questiona-se como se pode dizer que a pedra é dura (Stein ist hart), como se a palavra "dura" (hart) fosse uma realidade em si mesma. Quando anunciamos que a pedra é dura tudo se passa como se a "dureza" existisse por si só, não como um "estímulo completamente subjetivo". Como um segundo 
exemplo pretende denunciar a arbitrariedade das divisões que fazemos das coisas em gêneros sexuais (Geschlechtern). Nietzsche aponta que a palavra alemã Baum (árvore) pertence ao gênero masculino, enquanto que a palavra Pflanze (planta/vegetal) pertence ao gênero feminino, o que é incoerente, já que Baum é uma espécie de Pflanze (uma árvore é uma espécie de vegetal). Em último lugar analisa como a palavra "Schlange" (cobra) provém de uma designação que poderia servir para o "Wurme" (verme), ou seja, "sichwinden" (enrodilhar-se), no entanto, arbitrariamente e sem motivos que pudessem justificar categoricamente as designações, definimo-las tais como são. Por essas análises, Nietzsche pretende ter demonstrado o processo de formação de uma língua como uma série de delimitações e transferências arbitrárias. Neste processo, segundo o filósofo, “[...] nunca é a verdade que importa, nem a expressão adequada" (WL/VM 1, KSA 1.879).

Além da denúncia da incompatibilidade entre coisa em si e linguagem, Nietzsche pretende apontar também a inadequação da linguagem com a própria intuição, a partir da qual ela colheria seu material. Para o pensador, o processo de criação da linguagem consiste em um procedimento duplamente metafórico. Em um primeiro momento haveria a tradução de um estímulo nervoso em uma imagem (primeira metáfora). Em um segundo momento uma transformação dessa imagem em um som (segunda metáfora). $\mathrm{Ou}$ seja, para Nietzsche uma palavra é mais do que a reprodução ou representação de um estímulo nervoso, mas uma figuração e uma tradução, uma construção e transformação, de um estímulo nervoso em alguma coisa totalmente diferente dele, um som ${ }^{14}$.

14 Nietzsche faz uso da palavra alemã Abbildung para designar esse processo duplamente metafórico. Optamos por traduzi-la por "figuração", uma vez que deixa em destaque o parentesco do termo com Bild (figura, imagem, metáfora, símbolo, impressão), que por sua vez manter proximidade com a palavra inglesa build (construção, forma, constituição física). Além do emprego do substantivo Abbildung para indicar a natureza da palavra, o filósofo também utiliza os verbos alemães übertragen (transcrever, traduzir, transpor) e nachformen (transformar, remodelar) para indicar os processos que dão origem a essa figuração. 
Em sentido semelhante, opera a crítica de Schopenhauer aos que acreditam que a percepção se limitaria aos dados dos sentidos: "Que misera coisa é a mera sensação de nossos sentidos! Inclusive nos mais nobres órgãos dos sentidos não é mais do que um sentimento local, específico, capaz de variação dentro de sua espécie, que em si mesmo é sempre subjetivo e não pode conter nada objetivo, nem que se pareça com uma intuição ${ }^{15}$." Schopenhauer chama a atenção para a insuficiência da sensibilidade para justificação das representações intuitivas, para a qual elenca também o papel do entendimento, a partir da aplicação da lei da causalidade, como condição de constituição dos próprios objetos da intuição. Ou seja, para o pensador alemão, a intuição empírica é resultado de uma operação conjunta entre sensibilidade e entendimento. Como forma de ilustrar seu argumento, o filósofo explana sobre a relação entre as sensações provenientes do nervo ocular (a retina) e a constituição da visão. Segundo o filósofo, os olhos - os mais nobres dos órgãos dos sentidos - fornecem para o cérebro apenas duas imagens bidimensionais e invertidas, que por sua vez são convertidas, pelo e para o sujeito, em uma única imagem tridimensional e direita através da lei de causalidade, por meio da atividade do entendimento ${ }^{16}$.

Nesse caso, tanto Nietzsche quanto Schopenhauer denunciam a impossibilidade do conhecimento da coisa em si através do testemunho puro dos sentidos, da intuição empírica ou do pensamento racional (conceitual). A sensibilidade não pode sequer fornecer intuições completas por si só, necessitando da interferência da causalidade. A intuição empírica é sempre uma construção e limita-se ao âmbito do fenômeno. O conceito, por sua vez, é o resultado de uma delimitação de intuições, portanto, não pode ir além das próprias intuições, ou mesmo falar de intuições particulares com completa adequação. No entanto, Schopenhauer, diferente de Nietzsche, parece

15 Idem, 1998, p. 91.

16 Cf. Ibid., p. 99-104. 
contentar-se com a delimitação da verdade enquanto relação entre representações. Para Schopenhauer, podemos opor verdade e erro enquanto relação entre conceitos e objetos da representação. Se o pensamento racional não pode pensar a coisa em si, ainda lhe é permitido pensar o fenômeno, mesmo que não lhe seja permitido esgotar a riqueza da intuição com a pobreza do conceito.

A metafísica schopenhaueriana fornece os elementos que garantem a adequação entre conceitos e intuição empírica. Só é possível pensar cientificamente porque existe regularidade na efetivação das forças naturais. A regularidade das forças naturais está, em última análise, fundada no caráter atemporal e não espacial das Ideias metafísicas. Para Schopenhauer, as Ideias são os arquétipos das forças naturais e das espécies vegetais e animais. As Ideias, embora ainda possam ser representadas em um sujeito, não estão submetidas ao tempo, ao espaço e à causalidade, portanto, são eternas e imutáveis. As Ideias garantem a regularidade do mundo, posto que fazem o intermédio entre vontade (coisa em si) e representação empírica (uma das classes dos fenômenos), fundamentando as representações enquanto suas manifestações na matéria. A regularidade do mundo, por sua vez, permite a possibilidade de adequação entre o mundo empírico e o pensamento conceitual e, portanto, o progresso e objetividade das ciências da natureza. As ciências formais, como aritmética e geometria têm como garantia de objetividade e regularidade o próprio sujeito, na medida em que é ele que coloca tempo, espaço e causalidade na representação. A regularidade da lógica é colocada também pela razão no sujeito.

Tanto Nietzsche quanto Schopenhauer entendem o saber científico como um conhecimento conceitual, derivado direta ou indiretamente de intuições. Justamente por tratar-se de um conhecimento conceitual, segundo ambos os pensadores alemães, a ciência não pode alcançar a essência dos seus objetos. As intuições não apresentam sua própria essência e os conceitos são resultados de intuições esvaziadas de seu conteúdo. Como consequência, o saber científico, que se baseia nessas formas de apreensão da 
efetividade, redunda sempre em qualitates occultae, chegando assim ao limite de suas capacidades de explicação. Schopenhauer usa a noção de qualitas occulta para demonstrar a insuficiência do conceito de força para compreensão do enigma do mundo e da essência do efetivo ${ }^{17}$. A filosofia, na medida em que pretenda seguir o mesmo caminho da ciência, tampouco pode alcançar a compreensão da essência do mundo. Como Schopenhauer afirma: "Vemos, pois, que DE FORA jamais se chega à essência das coisas. Por mais que se investigue, obtêm-se tão-somente imagens e nomes. Assemelhamo-nos a alguém girando em torno de um castelo, debalde procurando sua entrada, e que de vez em quando desenha as fachadas. No entanto, este foi o caminho seguido por todos os filósofos que me antecederam ${ }^{18}$ ".

Sua compreensão da relação entre intuição e razão, leva Schopenhauer a buscar a decifração do enigma do mundo em outro lugar que não os conceitos - no próprio corpo. Para o filósofo, a vontade empírica e o corpo próprio, como objetidade da vontade, permitem compreender o mundo a partir de seus dois lados - como fenômeno e como coisa em si. A filosofia, na medida em que se fundamenta no conhecimento da experiência do próprio corpo, constitui-se como um saber expresso de maneira conceitual que pode falar mais apropriadamente da essência do efetivo. De acordo com a teoria schopenhaueriana, com a filosofia pode-se desvendar o enigma do mundo, ainda que a comunicação racional do conhecimento dessa essência seja extremamente problemático ${ }^{19}$. Uma vez que a linguagem em Schopenhauer equivale à expressão de conceitos, é impossível expressar adequadamente o conhecimento da coisa em si, que se dá a partir da experiência do próprio corpo. Segundo o pensador, a filosofia tem que se contentar em expor

17 Cf. Idem, 2005, p. 169-188.

18 Cf. Ibid., p. 156.

19 Cf. SCHOPENHAUER, A. El mundo como voluntad e representación, tomo II. In: Obras

- tomo segundo. Trad. E. Ovejero y Maury. Buenos Aires: El Ateneo, 1950, p. 209-218. 
esse conhecimento apenas de forma aproximada. Mas, na medida em que possa expressar inadequadamente a coisa em si, a filosofia pode acessar um campo da realidade vedado ao conhecimento científico. Sendo assim, filosofia e ciências se complementariam e teriam seus campos de atuação bem delimitados: a ciência atuaria em campos específicos da representação, a filosofia na experiência em geral e na metafísica ${ }^{20}$.

Nietzsche, por sua vez, procura demonstrar como frequentemente somos tentados pela linguagem a fazer hipóstases de conceitos em "formas primordiais" (Urformen) (Cf. WL/VM §1, KSA 1.885). $O$ autor de $O$ nascimento da tragédia parece implicitamente problematizar a noção de Ideia da metafísica schopenhaueriana. Mesmo o conhecimento metafísico que Schopenhauer propõe como solução da limitação da ciência não pode ser também um conhecimento da essência do mundo. Para Nietzsche, a teoria das Ideias de Schopenhauer não passaria de erro oriundo de processos puramente linguísticos, o mesmo ocorreria com o conceito de coisa em si e de vontade de vida. As Ideias não passariam de conceitos hipostasiados em realidades, assim como no exemplo da "dureza" da pedra, em que a "dureza" parece designar uma existência "em si". Ainda que Schopenhauer tenha feito diversos esforços para distinguir Ideias e $\operatorname{conceitos}^{21}$, para Nietzsche, as Ideias não seriam mais que conceitos hipostasiados.

Como consequência, o sentido e lugar da filosofia, tal como propostos por Schopenhauer, são deslocados. De acordo com Nietzsche, nem mesmo a filosofia schopenhaueriana teria ido além dos limites que ela mesma condenou nas outras filosofias, não pôde mais que obter imagens e nomes: "O surgimento da linguagem não

20 Cf. SCHOPENHAUER, A. Sobre la voluntad en la naturaleza. Trad. Unamuno. Buenos Aires: Siglo Veinte, 1947, p. 27-35.

21 As ideias são tomadas por Schopenhauer "em sentido platônico", ou seja, como arquétipos da representação: são entidades metafísicas que constituem o mundo como representação. Os conceitos, por outro lado, são resultados de abstrações da representação constituída, objetos de pensamento. 
procede, pois, logicamente, sendo que o inteiro material no qual e com o qual o homem da verdade, o pesquisador, o filósofo, mais tarde trabalha e edifica, tem sua origem, se não na Cucolândia das Nuvens [Wolkenkukuksheim] ${ }^{22}$, em todo caso não na essência das

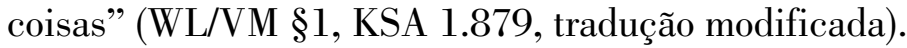

Para Nietzsche, mesmo a divisão do mundo em fenômeno e coisa em si não pode mais ser sustentada, seja à maneira de Kant ou à maneira de Schopenhauer. Como todo o conhecimento possível é tomado sempre como um conhecimento humano e derivado de suas configurações cognitivas, Nietzsche compreende a própria bipartição do mundo em coisa em si e fenômeno como uma divisão humana. Para o autor de $O$ nascimento da tragédia, a afirmação de que o mundo não corresponde às minhas intuições seria uma proposição tão dogmática quanto a afirmação que ele corresponda. Assim, como em Schopenhauer, está vedada à ciência a posição de produtora rigorosa de conhecimento verdadeiro da essência do mundo. No entanto, de maneira muito distinta da de Schopenhauer, também à metafísica é vedado o conhecimento das essências ${ }^{23}$.

$\mathrm{Na}$ medida em que mesmo falar da coisa em si (Ding an sich) em sentido rigoroso é problemático, falar de seu conceito correlato, o fenômeno (Erscheinung), também se torna um problema. Como uma forma de evitar o emprego abusivo de termos como "representação" (Vorstellung) e "fenômeno" (Erscheinung), excessivamente

22 Acreditamos que a expressão Wolkenkukuksheim possa ser relacionada diretamente a Schopenhauer, pois ele emprega a mesma expressão para reforçar o valor de sua filosofia, afirmando que o conhecimento da vontade não provêm da Wolkenkukuksheim (cf. Carta de 21 de agosto de 1852 a Frauenstädt, In: CACCIOLA, M. L. Schopenhauer e a questão do dogmatismo. São Paulo: Edusp, 1994, p. 174 e SCHOPENHAUER, A. Sobre o fundamento da moral. Trad. M. L. Cacciola. $2^{\text {a }}$ ed. São Paulo: Martins Fontes, 2001, p. 57-58).

23 Sobre o conhecimento da coisa em si, o Nachlass/FP 1871, 12[1], KSA 1.359, é claro: "Outrossim, toda a vida pulsional, o jogo dos sentimentos, sensações, afetos, atos de vontade nos é - como devo aqui acrescentar contra Schopenhauer - conhecida, mesmo na mais precisa introspecção, apenas como representação [Vorstellung], não em sua essência [Wesen]: e nos é permitido porventura dizer que a própria ,vontade ' de Schopenhauer não é senão a forma fenomenal mais geral de algo que aliás nos é completamente indecifrável". 
Moreira, F. S.

marcados por uma suposta relação com uma outra realidade (Realität), a coisa em si (Ding an sich), Nietzsche dá preferencia à palavra "aparência" (Schein), em detrimento das duas primeiras, cujo emprego caracteriza as obras de Kant e Schopenhauer. Nesse sentido pode ser entendida a seguinte afirmação: "A palavra fenômeno [Erscheinung] contém muitas tentações, daí eu evitá-la sempre que possível [...]" (WL/VM §1, KSA 1.884, tradução modificada).

Posto que é impossível entender a verdade como correspondência com a coisa em si, resta a Nietzsche a alternativa de abordar a verdade enquanto tautologia ou, ainda, enquanto convenção social.

Em uma passagem de Sobre verdade e mentira no sentido extramoral, Nietzsche assevera sobre a relação entre o homem e a verdade: "Se ele [o homem] não espera contentar-se com a verdade sob a forma da tautologia, isto é, como invólucros vazios [leeren Hülsen], então irá permutar eternamente ilusões por verdades" (WL/ VM 1, KSA 1.878, tradução modificada). Por "tautologia" Nietzsche entende o movimento que consiste em constatar a existência ou inexistência de um elemento em um objeto, sendo que a existência ou inexistência do elemento em questão já teria sido posta anteriormente pelo próprio aparato cognitivo do homem. Nesse sentido, a verdade ganha apenas o sentido de um esclarecimento, mas, como tal, pressupõe e se limita a movimentos antropomórficos. Por se limitar precisamente à exposição de "formas" previamente inseridas pelo homem no mundo, não se trata de um conhecimento da essência do mundo, mas o conhecimento de um invólucro vazio, esclarecimento da maneira como o homem conhece o mundo, não do mundo mesmo. Apenas enquanto tautologia a verdade pode ser compreendida como adequação de um juízo a um objeto.

A identificação da verdade como tautologia tem correlatos em Schopenhauer: quando Schopenhauer insere a noção de "verdade" dentro do âmbito racional e determina a existência de quatro formas de verdade, duas dessas formas referem-se exclusivamente ao aparato cognitivo do sujeito: a verdade metalógica e a verdade transcendental. Ambas possuem a forma tautológica denunciada 
por Nietzsche. As leis da lógica valem para todas as relações lógicas, mas isso não garante sua validade em relação à coisa em si, assim como as relações espaço-temporais valem absolutamente dentro de seu âmbito de atuação. Tanto a verdade metalógica quanto a verdade transcendental estão limitadas a declarar e identificar elementos que o sujeito põe no mundo, portanto, não podem valer para a coisa em si. Mesmo a validade objetiva constatada em relação à representação empírica com a aritmética e a geometria só demonstra aquilo que o próprio sujeito coloca no mundo. Tempo e espaço são formas puras da intuição, pertencem ao sujeito que percepciona o mundo, são inseridas no mundo pelo próprio sujeito. O problema que Schopenhauer pretende solucionar com a teoria da vontade é o do conteúdo dos objetos de primeira e quarta classes.

Embora semelhantes, a teoria apresentada por Nietzsche pretende ser mais radical do que a schopenhaueriana, na medida em que não reconhece um âmbito metafísico cognoscível. O conhecimento tautológico permanece sempre limitado ao âmbito humano e nada garante sua conformação com uma coisa em si, assim como também não é possível afirmar a sua não conformação. Como vimos, o enlace epistêmico traçado por Nietzsche impede que se possa falar da coisa em si em oposição ao fenômeno. O simples fato de que o conhecimento seja reconhecido como limitado a uma tautologia antropomórfica não autoriza a oposição como uma forma de referir-se de modo válido à coisa em si.

Mesmo a concordância dos homens com relação a elementos do mundo só demonstraria para Nietzsche a razoável conformidade entre os aparelhos cognitivos de cada um dos homens (Cf. Nachlass/FP 1872-1873, 19[157], KSA 7.468), mas não poderia atuar como prova da possibilidade de conhecimento da verdade. Para o pensador, é lícito supor que alguém com um aparato cognitivo diferente do homem percepcionaria o mundo de forma completamente diferente. Diante dessa hipótese, só seria permitido ao homem supor que seu aparato cognitivo poderia chegar à verdade do mundo, se tivesse o direito de supor que sua percepção é mais correta em 
relação à percepção de um outro ser. Mas, como Nietzsche assevera, não existe possibilidade de medir qual das várias percepções possíveis seria a mais correta.

Em último caso, Nietzsche passa a considerar a verdade como uma mentira fixada socialmente. Como vimos, a dissimulação (Verstellung) define a natureza do intelecto. Sendo o intelecto tradicionalmente considerado como a faculdade do aparato cognitivo responsável pela obtenção da verdade, considerá-lo como fundamentalmente dissimulador impossibilita a verdade como adequação. Como vimos também, em um estado natural, o homem não tem interesse pela verdade, pois é graças ao disfarce e a ilusão que o intelecto permite a sobrevivência do indivíduo. $\mathrm{O}$ homem em um estado natural não diferenciaria entre "verdade" e "mentira", pois essencialmente elas significariam a mesma coisa. No entanto, na medida em que ele estabelece relações sociais com os outros homens, faz-se necessária a fixação de algumas "mentiras" como "verdades". Nas palavras do autor:

Enquanto o indivíduo, num estado natural das coisas, quer preservar-se contra outros indivíduos, ele geralmente se vale do intelecto apenas para a dissimulação: mas, porque o homem quer, ao mesmo tempo, existir socialmente e em rebanho, por necessidade e tédio, ele necessita de um acordo de paz e empenha-se então para que a mais cruel bellum omnium contra omnes ao menos desapareça de seu mundo. Esse acordo de paz traz consigo, porém, algo que parece ser o primeiro passo rumo à obtenção daquele misterioso impulso à verdade. Agora, fixa-se aquilo que, doravante, deve ser "verdade", quer dizer, descobre-se uma designação uniformemente válida e impositiva das coisas, sendo que a legislação da linguagem fornece também as primeiras leis da verdade: pois aparece, aqui, pela primeira vez, o contraste entre verdade e mentira; o mentiroso serve-se das designações válidas, as palavras, para fazer o imaginário surgir como efetivo; ele diz, por exemplo, "sou rico", quando para seu estado justamente "pobre" seria a designação mais acertada. Ele abusa das convenções consolidadas por meio de trocas arbitrárias 
ou inversões dos nomes, inclusive. Se faz isso de uma maneira individualista e ainda por cima nociva, então a sociedade não confiará mais nele e, com isso, tratará de excluí-lo (WL/VM 1, KSA 1.877).

No entanto, ainda que sejam tomadas socialmente como opostas, não há diferença essencial entre verdade e mentira. Se, em um estado natural, o intelecto serve para dissimulação, em um estado social, algumas designações são tomadas como válidas e são impostas aos indivíduos como "verdade". Cria-se, com isso, um edifício conceitual antropomórfico, baseado em metáforas e metonímias absolutamente arbitrárias, mas com valor vinculativo, socialmente útil. Todavia, mesmo que doravante exista uma "verdade", ela não é pretendida por si só: o mentiroso só é excluído da sociedade na medida em que se mostra prejudicial a essa mesma sociedade. Chegar à verdade não é, portanto, apenas averiguar a validade de uma determinada relação conceitual, mas, antes disso, criar essa mesma validade. Mas, o hábito e o esquecimento fazem parecer que a verdade é um valor em si mesmo, escondem sua característica original, o seu valor moral.

Ainda não sabemos donde provém o impulso à verdade: pois, até agora, ouvimos falar apenas da obrigação de ser veraz, que a sociedade, para existir, institui, isto é, de utilizar metáforas habituais; portanto, dito moralmente: da obrigação de mentir conforme uma convenção consolidada, mentir em rebanho num estilo a todos obrigatório. $\mathrm{O}$ homem decerto se esquece que é assim que as coisas se lhe apresentam; ele mente, pois, da maneira indicada, inconscientemente e conforme hábitos seculares - e precisamente por meio dessa inconsciência, justamente mediante esse esquecer-se, atinge o sentimento da verdade. (WL/VM 1, KSA 1.881).

As teias conceituais que o homem cria são úteis na medida em que permitem um limitado domínio do mundo da aparência. É justamente em vista dessa relação de dominação que o homem cria a linguagem. Na medida em que o homem se interessa pelo mundo da 
aparência, uma pretensa coisa em si ("a pura verdade sem quaisquer consequências") não poderia constituir um interesse do formador da linguagem. $\mathrm{O}$ mundo da aparência é um fluxo, semelhante a um rio heraclitiano, sobre o qual o homem constrói teias de conceitos mais ou menos rígidas; rígidas o suficiente para que possa compreender sua figuração do mundo socialmente, flexíveis o suficiente para que não sejam completamente destroçadas pelo fluxo da efetividade.

No limite, Nietzsche considera também como uma forma de tautologia a verdade enquanto conformidade dos juízos com as teias e edifícios conceituais, portanto, dentro da vinculação entre os indivíduos no interior de uma sociedade. Em outras palavras, uma tautologia pode ser entendida em Nietzsche perceptiva ou linguisticamente. O investigador ou o filósofo é aquele que se apoia em tais jogos e edifícios conceituais para executar sua tarefa e produzir conhecimento. Nesse sentido, o filósofo e o cientista não só trabalham com o edifício e teias conceituais erguidos por um povo, mas também empregam seus serviços para fazer a manutenção dessas teias conceituais. A eficiência da ciência está fundada justamente na característica tautológica de suas verdades, sejam elas tautologias intuitivas ou linguísticas, como Nietzsche deixa entrever na seguinte passagem:

Quando alguém esconde algo detrás de um arbusto, volta a procurá-lo justamente lá onde escondeu e além de tudo o encontra, não há muito do que se vangloriar nesse procurar e encontrar: é assim que se dá com o procurar e encontrar a "verdade" no interior do domínio da razão. Se crio a definição de mamífero e, aí então, após inspecionar um camelo, declaro: veja, eis um mamífero, com isso, uma verdade decerto é trazida à plena luz, mas ela possui um valor limitado, digo, ela é antropomórfica de fio a pavio e não contém um único ponto sequer que fosse "verdadeiro em si", efetivo e universalmente válido, deixando de lado o homem" (WL/VM 1, KSA 1.883) ${ }^{24}$.

24 Embora no texto o exemplo citado não seja descrito como tautologia, essa relação fica mais 
A razão converte-se, portanto, em um instrumento útil, não para a descoberta da verdade, como se poderia supor, mas para um parcial domínio da natureza e o alcance de um sentimento da verdade. Para Nietzsche, nunca é a verdade mesma que impulsiona os homens ao conhecimento, mas justamente esse pathos da verdade, justamente a crença na verdade. Como Nietzsche afirma no Nachlass/FP 18721873, 19[175], KSA 7.473: “Quando se acredita possuir a verdade, a vida mais elevada e pura parece possível. A crença na verdade é necessária ao homem". Ou ainda, como é afirmado no Nachlass/FP 1873, 29[144], KSA 7.694: "Não há um impulso ao conhecimento e à verdade, mas tão-somente um impulso à crença na verdade. $\mathrm{O}$ conhecimento puro é desprovido de impulso".

A ciência e os edifícios conceituais são, para Nietzsche, ferramentas úteis que o homem cria para sua sobrevivência e convivência em rebanho. No entanto, ainda que possam proporcionar domínio sobre a natureza, esse domínio nunca é completo. $\mathrm{O}$ homem, sobretudo o pesquisador, encontra proteção nos edifícios conceituais que foram por ele construídos, no entanto, depois de construídos, tais edifícios não garantem a fixidez do mundo. Nas palavras de Nietzsche:

Se o homem de ação une sua vida à razão e a seus conceitos, para não ser arrastado e não se perder a si mesmo, o pesquisador, de sua parte, constrói sua cabana junto à torre da ciência para que possa prestar-lhe assistência e encontrar, ele próprio, amparo sob o baluarte à sua disposição. E, com efeito, ele necessita de amparo: pois há forças terríveis que lhe irrompem constantemente e que opõem às verdades científicas "verdades" de um tipo totalmente diferente com as mais diversas espécies de emblemas. (WL/VM 2, KSA 1.886).

clara no Nachlass/FP 1872-1873, 19[258], KSA 7.500: “[...] os conceitos só atestam aquilo que introduzimos neles e que, mais tarde, procuramos novamente sob eles - o que, no fundo, também é uma tautologia". Essa ampla concepção de tautologia permite que Nietzsche explique a aparente eficiência da ciência sem recorrer à teoria schopenhaueriana das Ideias metafísicas. 
A ciência, para Nietzsche, não é responsável para criação de novas metáforas e novos edifícios conceituais, mas apenas trabalha com os edifícios já construídos, fazendo sua manutenção. O desenvolvimento científico representa, portanto, o desenvolvimento de um edifício conceitual determinado e sua fixação no interior de um povo. Todavia, o desenvolvimento da ciência não representa o estancamento do impulso criador de metáforas no homem, nem sequer o verdadeiro domínio do mundo. Tal impulso, considerado o impulso fundamental do homem, é transposto para outro âmbito de atuação: o mito e a arte. $\mathrm{O}$ processo mesmo de formação da linguagem é reconhecido por Nietzsche como um impulso "poético".

Temos aqui uma contraposição fundamental com a teoria schopenhaueriana. Nietzsche não opõe vontade e intelecto, pelo contrário, denuncia em toda a atividade do intelecto um interesse, um impulso em direção ao pathos da verdade. Nietzsche não aceita a noção de objetividade pura do intelecto, em qualquer instância. Para Schopenhauer, a oposição entre vontade e intelecto está no fundamento da atividade estética; tanto o espectador quanto o artista estão relacionados com uma contemplação desinteressada, destituída de impulso ${ }^{25}$. Por outro lado, para o jovem Nietzsche, a atividade da intuição ou da razão são sempre atividades pulsionais, o que não permite, já no primeiro período, que compreenda a arte nos mesmos termos de Schopenhauer. Portanto, a atividade estética é, segundo a concepção nietzschiana, resultado do impulso transfigurador do homem, criador de novas imagens, novas metáforas.

Em função da contraposição entre a razão e intuição, Nietzsche estabelece uma tipologia dos homens. Passa a considerar aquele que fundamenta suas ações principalmente na razão como o homem racional (vernünftige Mensch), contraposto ao homem que baseia suas ações na intuição, o homem intuitivo (intuitive Mensch). Ambos os tipos humanos teriam o mesmo desejo: exercer domínio

25 Cf. SCHOPENHAUER, 2005, p. 264-265 e p. 306-310. 
sobre a vida, mas "[...] um [o homem racional] com medo da intuição, outro [o homem intuitivo] ridicularizando a abstração" (WL/ VM 2, KSA 1.889). Segundo Nietzsche, além de ferramentas e métodos de domínio diferentes, os dois tipos se distinguem também pelos motivos pelos quais agem. $\mathrm{O}$ homem racional procura utilizar-se dos edifícios e teias conceituais, próprios da razão. Ele procuraria "encarar as mais básicas necessidades mediante precaução, sagacidade e regularidade", por meio do uso de conceitos. O homem intuitivo, pelo contrário, não encontraria na existência "necessidades", razão pela qual encarraria a vida como um "herói sobre-exaltado", lançando-se sobre ela, sem exigir da vida coerência e segurança. O homem racional procuraria apenas afastar o sofrimento, procurando a ausência de dor. $\mathrm{O}$ homem intuitivo, pelo contrário, é irracional na felicidade e no sofrimento, assim como frequentemente não aprende com a experiência do sofrimento.

Ainda que Nietzsche pareça atribuir superioridade ao homem intuitivo frente ao homem racional, não o faz explicitamente, apenas por alguns indícios desconexos. Trabalhamos com a hipótese interpretativa de que, neste momento da produção teórica de Nietzsche, falta um critério com o qual o filósofo possa avaliar cada um dos tipos apresentados.

Em síntese: Em Sobre verdade e mentira no sentido extramoral, Nietzsche se aproxima muito da dicotomia schopenhaueriana e da relação entre intuição e razão. Todavia, promove alterações na concepção básica de linguagem e de razão. Como consequência necessária desta mudança de perspectiva, o conceito de verdade sofre alterações também. Nietzsche passa a desconsiderar a possibilidade de construção de uma verdadeira metafísica, e mesmo considerar a verdade como adequação à efetividade se torna problemático, uma vez que a efetividade não se conforma ao conceito e à linguagem. Tal abordagem do problema epistêmico da verdade leva Nietzsche a considerá-la a partir da perspectiva moral, ou seja, como construção social, uma fixação arbitrária e imperfeita da efetividade. Soma-se a essa modificação do conceito mesmo 
de verdade, a compreensão que Nietzsche faz do próprio conhecimento e, como consequência, da consciência. Ele considera o intelecto como um impulso; o que o leva a questão-chave "como é possível um puro impulso para o conhecimento?". Em outras palavras, como é possível um conhecimento desinteressado?

Schopenhauer, por sua vez, não teria entendido o conhecimento como resultado de um impulso. Não há propriamente um impulso de conhecimento em Schopenhauer, mas uma vontade auxiliada pelo conhecimento, ou ainda, um conhecimento guiado pela vontade. $\mathrm{O}$ conhecimento e a consciência, quando livres do jugo da vontade, podem se converter em um "espelho do mundo", em uma contemplação desinteressada. Por sua vez, Nietzsche, na medida em que entende o próprio conhecer como um impulso, compreende que todo conhecimento tem que ser necessariamente interessado. Não existiria, desde o primeiro Nietzsche, a possibilidade de um conhecimento desinteressado e, portanto, não existiria a possibilidade de um verdadeiro conhecimento metafísico. $\mathrm{O}$ impulso para a verdade não é um puro impulso, mas uma "vontade de verdade", um impulso em direção ao pathos da verdade. Ao entender a impossibilidade do conhecimento emancipado da vontade, Nietzsche não sustenta a oposição schopenhaueriana entre vontade e intelecto, mas preservaria a relação entre intuição e razão.

Outra mudança significativa entre os dois pensadores alemães consiste na relação entre ciência e filosofia. Em Schopenhauer, a ciência e a filosofia se complementam, cada qual operando em campos de pesquisa distintos. Mas, no primeiro Nietzsche, o pesquisador e o filósofo são descritos como homens que trabalham com as teias de conceitos, cabendo à arte e ao mito a criação ou destruição de teias de conceitos. No limite, a proposta de aproximação entre a filosofia e a arte permanece em ambos os filósofos, mas a interpretação da essência e do papel próprio da arte já representa uma separação radical do primeiro Nietzsche em relação a Schopenhauer. 


\begin{abstract}
We propose to investigate the concepts of truth and language in Nietzsche's first period and demonstrate how the critic of language is linked with the Schopenhauer's concepts of will, intellect, intuition and reason. We think that young Nietzsche interpreted the intellect as an impulse and identified the concepts of reason and language. That results in the rejection of the propose of metaphysics of will and caused expressive changes in the interpretation of roles of the arts, the sciences and the philosophy.

Keywords: Schopenhauer - Nietzsche - truth - language - intuition - intellect
\end{abstract}

\title{
referências bibliográficas
}

1. CACCIOLA, M. L. Schopenhauer e a questão do dogmatismo. São Paulo: Edusp, 1994.

2. NIETZSCHE, F. W. Sämtliche Werke Historisch-kritische Ausgabe. Edição organizada por G. Colli e M. Montinari. Berlim: Walter de Gruyter, 1994.

3. __ Sobre verdade e mentira. Trad. F. M. Barros. São Paulo: Hedra, 2007.

4. SCHOPENHAUER, A. Sobre la voluntad en la naturaleza. Trad. M. de Unamuno. Buenos Aires: Siglo Veinte, 1947.

5. _ El mundo como voluntad e representación. In: Obras - tomo segundo. Trad. E. Ovejero y Maury. Buenos Aires: El Ateneo, 1950, t. II.

6. __ Zürcher Ausgabe Werke in zehn Bänden. Zürich: Diogenes, 1977.

7. __ Respuestas Filosóficas a la ética, a la ciencia y a la religión. Trad. Miguel Urquiola. Madrid: EDAF, 1996.

8. _ De la cuádruple raíz del principio de razón. Trad. L-E. Palacios. Madrid: Gredos, 1998.

9. _. Sobre o fundamento da moral. Trad. M. L. Cacciola. $2^{\mathrm{a}}$ ed. São Paulo: Martins Fontes, 2001.

10. . O mundo como vontade e representação. Tomo I. Tradução de J. Barboza. São Paulo: Unesp, 2005.

11. _. A arte de escrever. Trad. Pedro Süssekind. Porto Alegre: L\&PM, 2009.

Artigo recebido para publicação em 10/08/2012.

Artigo aceito para publicação em 20/09/2012.

Cad. Nietzsche, São Paulo, n. 33, p. 273-300, 2013. 
